\title{
Illicit Methylphenidate Use in an Undergraduate Student Sample: Prevalence and Risk Factors
}

\author{
Christian J. Teter, Pharm.D., Sean Esteban McCabe, Ph.D., Carol J. Boyd, Ph.D., and \\ Sally K. Guthrie, Pharm.D.
}

Study Objectives. To assess the prevalence of illicit methylphenidate use among undergraduate college students at a large university, and to identify alcohol and other drug use behaviors, as well as the negative consequences and risk factors, associated with illicit methylphenidate use.

Design. Internet survey.

Setting. Large public university.

Subjects. Thirty-five hundred randomly selected undergraduate students.

Measurements and Main Results. Of the 2250 students who completed the survey, 3\% reported past-year illicit methylphenidate use. Illicit methylphenidate users were significantly more likely to use alcohol and drugs and report adverse alcohol- and drug-related consequences than prescription stimulant users or students who did not use stimulants. Undergraduate men and women were equally likely to report past-year illicit methylphenidate use. Weekly party behavior was significantly associated with past-year illicit methylphenidate use.

Conclusion. Illicit use of prescription-only stimulants on college campuses is a potentially serious public health issue. More work is needed to promote understanding and awareness of this problem among clinicians and researchers.

(Pharmacotherapy 2003;23(5):609-617)

The misuse of alcohol and illicit drugs among traditional-age undergraduate students remains a major public health problem for American colleges and universities. ${ }^{1-4}$ College students who misuse alcohol and other drugs experience significantly higher rates of negative consequences than students who do not use these substances. ${ }^{5-8}$

From the College of Pharmacy (Drs. Teter and Guthrie), the Substance Abuse Research Center (Drs. Teter, McCabe, and Boyd), the School of Nursing and Women's Studies (Dr. Boyd), and the Department of Psychiatry (Dr. Guthrie), The University of Michigan, Ann Arbor, Michigan.

Supported by the University of Michigan and the National Institute on Drug Abuse, National Institutes of $\mathrm{H}$ ealth (National Research Service Award T32 DA 07267).

Address reprint requests to Christian J. Teter, Pharm.D., BCPP, The University of Michigan, College of Pharmacy, Room 4017, 428 Church Street, Ann Arbor, MI 481091065; e-mail: cjteter@umich.edu.
Recent years have brought increasing evidence that college students are abusing not only al cohol but also prescription drugs. ${ }^{2}$ Indeed, this abuse appears to coincide with the increasing number of prescriptions that have been written for psychostimulants. ${ }^{9}$ Methylphenidate (Ritalin; Novartis Pharmaceuticals Corp, East Hanover, $\mathrm{NJ}$ ) and other psychostimulants, such as Damphetamine, are the preferred pharmacotherapy for treating attention-deficit-hyperactivity disorder (ADHD). Although methylphenidate is highly effective for the treatment of ADHD, ${ }^{10}$ it has potential for abuse and diversion. ${ }^{11}$ The licit and illicit use of methylphenidate has increased dramatically over the past 10 years, ${ }^{9}, 12$ but research on patterns and consequences of its use has been limited in the college population. We sought to assess the prevalence of illicit 
methylphenidate use among undergraduate students at a large public university. Other goals of this study were to identify alcohol and drug use behaviors, as well as the negative consequences and risk factors, associated with illicit methylphenidate use.

\section{Methods}

The University of Michigan's institutional review board approved the protocol for this study, and all respondents gave informed consent. The study was conducted during a 1month period between March and April of 2001, drawing on a total undergraduate population of 21,055 full-time students $(10,732$ women and 10,323 men). A random sample of 3500 fulltime University of Michigan undergraduate students was drawn from the Registrar's Office. The students were sent a letter through e-mail describing the study and inviting recipients to self-administer the Student Life Survey. Students were told to access the Web survey by clicking on an e-mail link.

\section{Survey}

The Student Life Survey was developed and pilot tested in 1993. It draws from items in the Monitoring the Future (MTF) study, ${ }^{13}$ the Core Alcohol and Drug Survey, ${ }^{5}$ and the College Alcohol Study. ${ }^{14}$ Design, procedures, and reliability measures pertaining to the Student Life Survey are described in more detail el sewhere. ${ }^{15,16}$

The survey was designed to collect demographic information, including sex, age, primary ethnic origin, primary religious affiliation, grade point average, fraternity or sorority affiliation, average annual family income, and living arrangements. It also queried students about alcohol and drug use, prescription drug use, sexual behavior, and adverse alcohol- and drug-related consequences.

Illicit drug use was assessed by the following question: "Have you ever used the following types of drugs... (a) in your lifetime, (b) during the past 12 months, or (c) during the past 30 days? Do not include drugs used under a doctor's prescription. (Check all that apply)." The following substances were listed as possible answers: "marijuana, cocaine in any form, LSD, other psychedelics, amphetamines or methamphetamine, crystal meth, Ritalin, downers, tranquilizers, heroin, other narcotics, inhalants, Ecstasy (MDMA), GHB, Rohypnol, anabolic steroids, and other (please specify)." For those drug categories that included a broad range of substances, examples were given for clarification. For example, for "other narcotics," examples given were Vicodin, codeine, Demerol, Percodan, methadone, opium, and morphine. Respondents were given two response categories (yes and no). Endorsement of "yes" was defined as illicit drug use. We created two illicit drug indexes for each student by summing the number of responses indicating that the student had used an illicit substance in the past year or past month, respectively. If respondents indicated they had used a drug in their lifetime, they received a follow-up question asking when they began using the specific drug. The four response categories were elementary school, junior high school, high school, and college. Another index for each student was created to assess the start of drug use before entering college. This index reflected the summation of the number of illicit drugs a student had used in high school or earlier.

To assess prescription drug use, the survey asked the following question: "Based on a doctor's prescription, have you ever used the following types of drugs... (a) in your lifetime? or (b) in the past 12 months?" Five categories of prescription drugs were identified: stimulants (e.g., weight loss pills, Ritalin), sleeping aids (e.g., Halcion), minor tranquilizers (e.g., Valium, Ativan), prescription analgesics (e.g., codeine, Darvon, Tylenol No. 3), and antidepressants (e.g., Prozac, Paxil, Zoloft, Luvox). Respondents were given two response categories (yes and no). An endorsement of "yes" was defined as prescription drug use.

Primary and secondary alcohol-related consequences were assessed by items adapted from national studies of alcohol and drug use among college students. ${ }^{5,14}$ For example, primary consequences associated with drinking included missing a class, developing a hangover, damaging property, being hurt or injured, and having unplanned sex. The response scale for each item ranged from 1 (never) to 4 ( 6 or more times). A primary alcohol-related consequences index was created by summing each respondent's scores for the 23 survey items addressing primary alcohol-related consequences in the past year. Secondary consequences were assessed using 10 questions that explored consequences associated with others' use of alcohol in the past year. Examples were disrupted sleep, experienced an unwanted sexual advance by someone drunk or high, and had to take care of someone with a drinking or drug problem. The response scale for each item ranged from 1 (never) to 5 (10 or more 
Table 1. Demographics and Alcohol or Drug Use Behaviors of Illicit Methylphenidate Users, Prescription Stimulant Users, and Nonstimulant Users

\begin{tabular}{|c|c|c|c|c|}
\hline Variable & $\begin{array}{l}\text { Past-Year Illicit } \\
\text { M ethylphenidate } \\
\text { Users (\%) } \\
(n=57)\end{array}$ & $\begin{array}{c}\text { Past-Year } \\
\text { Prescription } \\
\text { Stimulant } \\
\text { Users (\%) } \\
(n=25)\end{array}$ & $\begin{array}{l}\text { Past-Year } \\
\text { Nonstimulant } \\
\text { Users (\%) } \\
(n=2168)\end{array}$ & $\begin{array}{l}\text { Statistically Significant } \\
\text { Differences Between } \\
\text { the Three Groups }\end{array}$ \\
\hline $\begin{array}{l}\text { Sex } \\
\text { Women } \\
\text { Men }\end{array}$ & $\begin{array}{l}59.6 \\
40.4\end{array}$ & $\begin{array}{l}56.0 \\
44.0\end{array}$ & $\begin{array}{l}56.2 \\
43.8\end{array}$ & NS \\
\hline $\begin{array}{l}\text { Class year } \\
\text { Freshman } \\
\text { Sophomore } \\
\text { Junior } \\
\text { Senior }\end{array}$ & $\begin{array}{r}35.7 \\
5.4 \\
23.2 \\
35.7\end{array}$ & $\begin{array}{l}12.5 \\
20.8 \\
45.8 \\
20.8\end{array}$ & $\begin{array}{l}23.5 \\
25.5 \\
28.2 \\
22.8\end{array}$ & b \\
\hline $\begin{array}{l}\text { Race } \\
\text { African-American } \\
\text { Asian } \\
\text { White } \\
\text { Other }\end{array}$ & $\begin{array}{r}1.8 \\
1.8 \\
84.2 \\
12.3\end{array}$ & $\begin{array}{c}0 \\
0 \\
88.0 \\
12.0\end{array}$ & $\begin{array}{r}4.5 \\
15.2 \\
70.4 \\
9.8\end{array}$ & NS \\
\hline $\begin{array}{l}\text { Got drunk in high school or before } \\
\text { Binge drinking in the past } 2 \text { weeks } \\
\text { Marijuana use in high school or before } \\
\text { Marijuana use in the past year } \\
\text { Ecstasy (MDMA) use in the past year } \\
\text { Any cigarette use in the past month }\end{array}$ & $\begin{array}{r}98.2 \\
98.2 \\
91.2 \\
100.0 \\
57.9 \\
77.2\end{array}$ & $\begin{array}{l}54.2 \\
69.6 \\
50.0 \\
50.0 \\
12.5 \\
32.0\end{array}$ & $\begin{array}{r}58.3 \\
48.3 \\
28.1 \\
29.9 \\
5.3 \\
22.0\end{array}$ & $\begin{array}{l}b, c \\
b, c, d \\
b, c \\
b, c \\
b, c \\
b, c\end{array}$ \\
\hline
\end{tabular}

MDMA =3,4-methylenedioxymethamphetamine.

${ }^{a} \mathrm{p} \varangle 0.01$, based on $x^{2}$.

blllicit methylphenidate users differed from nonstimulant users.

clllicit methylphenidate users differed from prescribed stimulant users.

dPrescribed stimulant users differed from nonstimulant users.

times). A secondary alcohol-related consequences index was created by summing each respondent's scores for the 10 items in this category.

For the survey to qualify as being completed, the student must have answered at least two thirds of the questions, including those addressing demographic characteristics, alcohol use, illicit drug use, prescription drug use both as prescribed by a doctor and not as prescribed, and adverse alcohol- and drug-related consequences. After completing the survey, the student would receive a $\$ 10$ gift certificate to a local bookstore.

\section{Statistical Analysis}

We used $\chi^{2}$ tests to compare student demographics, prescription drug use, and alcohol and drug use across three distinct groups, with "the past 12 months" as the time frame. The three groups were as follows: undergraduate students who reported taking methylphenidate not as prescribed by a doctor (illicit use), undergraduate students who reported taking stimulant drugs as prescribed by a doctor, and undergraduate students who reported no stimulant use. In addition to $\chi^{2}$ tests, 1-way analyses of variance were used to compare illicit methylphenidate users, prescription stimulant users, and nonstimulant users across several continuous measures. Post hoc pairwise comparisons were conducted using Tukey's honestly significant difference test. We set the $\alpha$ a priori at 0.05 . Finally, multivariate logistic regression was used to assess factors that might be associated with illicit methylphenidate use, using two separate models for lifetime and pastyear use. All analyses were conducted with SPSS software (SPSS Inc., Chicago, IL).

\section{Results}

The response rate was $64 \%$ ( $70 \%$ for women, $58 \%$ for men), which was better than average when compared with national college-based studies of alcohol and other drugs. ${ }^{4}$ The total sample consisted of 2250 undergraduate students with a mean \pm SD age of $20.07 \pm 1.70$ years. Table 1 shows respondents' demographics and alcohol or drug use behaviors. Prevalence rates for various illicit substances in the past year 
Table 2. Alcohol or Drug Use Behaviors and Related Negative C onsequences Associated with Illicit Methylphenidate U se

\begin{tabular}{|c|c|c|c|c|}
\hline & $\begin{array}{l}\text { Past-Year Illicit } \\
\text { M ethylphenidate } \\
\text { Users } \\
(n=57)\end{array}$ & $\begin{array}{l}\text { Past-Year } \\
\text { Prescription } \\
\text { Stimulant } \\
\text { Users } \\
(n=25)\end{array}$ & $\begin{array}{c}\text { Past-Year } \\
\text { Nonstimulant } \\
\text { Users } \\
(n=2168)\end{array}$ & $\begin{array}{c}\text { Statistically } \\
\text { Significant } \\
\text { Differences } \\
\text { Between the } \\
\text { Three Groups }\end{array}$ \\
\hline $\begin{array}{l}\text { No. of illicit drugs used in the past year, } \\
\text { excluding illicit methylphenidate }(0-16)\end{array}$ & $3.84 \pm 0.14$ & $1.25 \pm 0.21$ & $0.49 \pm 0.02$ & $b, c, d$ \\
\hline $\begin{array}{l}\text { No. of illicit drugs used in the past month, } \\
\text { excluding illicit methylphenidate }(0-16)\end{array}$ & $1.95 \pm 0.08$ & $0.67 \pm 0.13$ & $0.22 \pm 0.01$ & $b, c, d$ \\
\hline $\begin{array}{l}\text { No. of pre-college illicit drugs used, } \\
\text { excluding illicit methylphenidate (0-16) }\end{array}$ & $2.30 \pm 0.13$ & $1.10 \pm 0.20$ & $0.44 \pm 0.02$ & $b, c, d$ \\
\hline No. of drinks/occasion in the past 30 days ( $0-12)$ & $7.02 \pm 0.37$ & $4.70 \pm 0.58$ & $4.10 \pm 0.06$ & $b, c$ \\
\hline $\begin{array}{l}\text { Primary al cohol- or drug-related } \\
\text { consequences index }(0-23)\end{array}$ & $9.68 \pm 0.52$ & $4.39 \pm 0.81$ & $3.90 \pm 0.09$ & $b, c$ \\
\hline $\begin{array}{l}\text { Secondary alcohol- or drug-related } \\
\text { consequences index }(0-10)\end{array}$ & $5.28 \pm 0.31$ & $3.60 \pm 0.46$ & $3.20 \pm 0.05$ & $b, c$ \\
\hline Grade point average $(0-4.0)$ & $3.13 \pm 0.06$ & $3.33 \pm 0.09$ & $3.28 \pm 0.01$ & b \\
\hline
\end{tabular}

Data are mean \pm SE

al-way analysis of variance followed by post hoc Tukey's honestly significant difference test, $p \varangle 0.05$.

blllicit methylphenidate users differed from nonstimulant users.

cllicit methylphenidate users differed from prescription stimulant users.

dPrescription stimulant users differed from nonstimulant users.

within our sample were consistent with the findings of a comparable national sample from the Monitoring the Future study. ${ }^{2}$ of the 57 students who reported illicit methylphenidate use in the past year, $2 \%$ began taking methylphenidate in junior high, whereas 19\% started in high school, and $79 \%$ began in college. None of the students who reported lifetime or past-year illicit methylphenidate use injected the drug, and no information was available on intranasal administration.

Illicit methylphenidate users were significantly more likely to have used various other substances in the past year and the past month than either prescription stimulant users or nonstimulant users. In particular, $100 \%$ and $58 \%$ of the pastyear illicit methylphenidate users had used marijuana and Ecstasy (MDMA [3,4-methylenedioxymethamphetamine]), respectively, in the past year. Moreover, $98 \%$ of illicit methylphenidate users reported a binge drinking episode in the past 2 weeks.

Illicit methylphenidate users reported consuming significantly more mean drinks/occasion in the past month than either prescription stimulant users or nonstimulant users. Furthermore, illicit methylphenidate users reported having taken 3 times the number of illicit drugs, other than methylphenidate, in the past year as were used by prescription stimulant users, and 8 times the number of illicit drugs used by nonstimulant users in the past year (Table 2). Illicit methylphenidate users also reported significantly higher mean levels of negative primary and secondary alcohol- or drugrelated consequences in the past year than prescription stimulant users or nonstimulant users. In fact, while illicit methylphenidate users reported significantly higher rates of every individual primary and secondary consequence relative to prescription stimulant users and nonstimulant users, there were no statistically significant differences between prescription stimulant users and nonstimulant users, with the exception of one primary consequence: prescription stimulant users were more likely to report missing a class due to drinking (44\%) than nonstimulant users (25\%).

Our $\chi^{2}$ analysis revealed that weekly party behavior, having multiple sexual partners, fraternity or sorority affiliation, and family income were all significantly associated with both lifetime and past-year illicit methylphenidate use ( $p<0.001$ for all associations, results not shown). Most notably, the prevalence of illicit methylphenidate use in the past year was 14\% among students who reported 10 or more hours of weekly party behavior.

Multivariate Results

As shown in Table 3, multivariate logistic 
Table 3. Multivariate Logistic Regression Results Examining Correlates of Illicit Methylphenidate Use During Lifetime and Past Year (two separate models)

\begin{tabular}{|c|c|c|c|c|}
\hline \multirow[b]{2}{*}{ Characteristic } & \multicolumn{2}{|c|}{$\begin{array}{c}\text { Lifetime } \\
\text { Illicit Methylphenidate Use }\end{array}$} & \multicolumn{2}{|c|}{$\begin{array}{c}\text { Past-Year } \\
\text { Illicit M ethyl phenidate Use }\end{array}$} \\
\hline & Adjusted ORa & $95 \% \mathrm{Cl}$ & $\overline{\text { Adjusted OR }} \mathrm{R}^{\mathrm{a}}$ & $95 \% \mathrm{Cl}$ \\
\hline \multicolumn{5}{|l|}{$\begin{array}{l}\text { Sex } \\
\end{array}$} \\
\hline Men & 1.00 & & 1.00 & \\
\hline Women & 0.74 & $0.48-1.15$ & 1.00 & $0.55-1.85$ \\
\hline \multicolumn{5}{|l|}{ Race } \\
\hline White & 1.00 & & 1.00 & \\
\hline Nonwhite & 0.59 & $0.32-1.07$ & 0.76 & $0.34-1.71$ \\
\hline \multicolumn{5}{|l|}{ Fraternity or sorority affiliation } \\
\hline Fraternity or sorority member & 1.00 & & 1.00 & \\
\hline Nonmember & 0.66 & $0.37-1.15$ & 0.70 & $0.35-1.42$ \\
\hline \multicolumn{5}{|l|}{ Religious affiliation } \\
\hline Jewish & 1.00 & & 1.00 & \\
\hline Catholic & 0.83 & $0.41-1.68$ & 0.55 & $0.24-1.28$ \\
\hline None & 1.38 & $0.66-2.88$ & 0.76 & $0.30-1.94$ \\
\hline Other & 1.06 & $0.52-2.15$ & $0.37^{\mathrm{b}}$ & $0.15-0.95$ \\
\hline \multicolumn{5}{|l|}{ Family income (\$) } \\
\hline$<50,000$ & 1.00 & & 1.00 & \\
\hline $50,000-99,999$ & 0.95 & $0.39-2.33$ & 0.99 & $0.22-4.43$ \\
\hline $100,000-249,999$ & 1.42 & $0.62-3.22$ & 2.13 & $0.55-8.15$ \\
\hline$\geq 250,000$ & $2.89^{b}$ & $1.19-7.04$ & 2.81 & $0.69-11.49$ \\
\hline Don't know & 0.68 & $0.25-1.84$ & 1.27 & $0.29-5.53$ \\
\hline \multicolumn{5}{|l|}{ Weekly party behavior (hrs) } \\
\hline None & 1.00 & & 1.00 & \\
\hline $1-4$ & 1.01 & $0.47-2.17$ & 1.91 & $0.40-9.04$ \\
\hline $5-9$ & $2.32^{\mathrm{b}}$ & $1.06-5.08$ & $5.10^{\mathrm{b}}$ & $1.10-23.53$ \\
\hline$\geq 10$ & $4.35^{c}$ & $1.78-10.64$ & $12.62^{c}$ & $2.56-62.19$ \\
\hline \multicolumn{5}{|l|}{ Grade point average } \\
\hline$<2.5$ & 1.00 & & 1.00 & \\
\hline $2.5-2.9$ & 0.55 & $0.19-1.61$ & 0.34 & $0.09-1.27$ \\
\hline $3.0-3.4$ & 0.71 & $0.27-1.85$ & 0.43 & $0.14-1.32$ \\
\hline$\geq 3.5$ & 0.54 & $0.20-1.46$ & $0.20^{c}$ & $0.06-0.68$ \\
\hline \multicolumn{5}{|l|}{ Class year } \\
\hline Freshmen & 1.00 & & 1.00 & \\
\hline Sophomore & 0.49 & $0.20-1.18$ & $0.10^{\mathrm{b}}$ & $0.02-0.59$ \\
\hline Junior & 0.53 & $0.20-1.42$ & 0.32 & $0.06-1.87$ \\
\hline Senior & 0.98 & $0.36-2.63$ & 0.52 & $0.09-3.02$ \\
\hline \multicolumn{5}{|l|}{ Living arrangement } \\
\hline Residence hall & 1.00 & & 1.00 & \\
\hline Fraternity or sorority & 0.44 & $0.12-1.58$ & 0.56 & $0.06-5.01$ \\
\hline House or apartment & 1.16 & $0.49-2.74$ & 1.66 & $0.31-8.84$ \\
\hline Other & 2.16 & $0.63-7.42$ & 1.72 & $0.13-22.50$ \\
\hline \multicolumn{5}{|c|}{ No. of sexual partners in the past year } \\
\hline None & 1.00 & & 1.00 & \\
\hline 1 & $2.31^{c}$ & $1.25-4.25$ & $1.42^{\mathrm{b}}$ & $0.59-3.41$ \\
\hline 2 & $3.78^{d}$ & $1.86-7.68$ & $3.23^{d}$ & $1.29-8.13$ \\
\hline 3 & $7.00^{\mathrm{d}}$ & $3.17-15.44$ & $5.67^{c}$ & $2.02-15.89$ \\
\hline 4 & $3.85^{b}$ & $1.25-11.92$ & $7.30^{\mathrm{d}}$ & $2.09-25.53$ \\
\hline$\geq 5$ & $6.19^{d}$ & $2.32-16.51$ & $7.35^{d}$ & $2.26-23.85$ \\
\hline
\end{tabular}

$\mathrm{OR}=$ odds ratio; $\mathrm{Cl}=$ confidence interval.

a dds ratios are adjusted for all other correlates.

${ }^{\mathrm{b}} \mathrm{p}<0.05$.

${ }_{p}<<0.01$.

${ }^{d} p<0.001$.

regression revealed that after controlling for the identified student characteristics, students who reported lifetime or past-year illicit methyl- phenidate use were significantly more likely than other students to engage in party behavior of more than 5 hours/week. In addition, after we 
controlled for the other variables, the data showed no significant associations between sex, race, social fraternity or sorority affiliation, or living arrangement with past-year or lifetime illicit methylphenidate use.

\section{Discussion}

Approximately $3 \%$ (57 students) of our sample of 2250 undergraduate college students had used methylphenidate in the past year without a doctor's prescription. This is consistent with the limited prevalence data published in the literature regarding illicit use of methylphenidate among adolescents. For instance, the Monitoring the Future study, which tracked illicit methylphenidate use in nationally representative samples of 12th grade students, found that illicit use has increased dramatically over the past 5 years, with a current annual prevalence of approximately $3 \% .^{12}$ Similarly, an Indiana survey revealed that approximately $4 \%$ of 12 th grade students in that state had used nonprescribed methylphenidate in the past year. ${ }^{17}$ The Monitoring the Future and Indiana sample populations both consisted of 12 th grade students, not college populations; in fact, limited data have been published on illicit methylphenidate use among college students. One single-institution study found that more than $16 \%$ of the students surveyed (283 students) at a 4-year public liberal arts college had tried methylphenidate for nonmedical purposes. ${ }^{18}$ Because there are significant differences in drugusing behaviors among different colleges and universities, ${ }^{4}$ the extent of illicit methylphenidate use among college students nationwide remains unknown, although it appears to be a growing problem on some campuses.

Further evidence illustrating this potentially serious public health issue comes from a variety of anecdotal case reports of methylphenidate abuse in the literature, ${ }^{19-24}$ as well as empirical evidence that methylphenidate has abuse potential. ${ }^{25}$ According to an extensive literature review, in 48 of 60 studies ( $80 \%$ ) assessing the reinforcing, discriminative-stimulus, or subjective effects of methylphenidate in nonhuman and human subjects, methylphenidate appeared to have an abuse potential similar to that of D-amphetamine and cocaine. ${ }^{25}$ Furthermore, methylphenidate and cocaine show similar pharmacokinetic and pharmacodynamic profiles in the human brain ${ }^{26}$ and have very similar actions at the dopamine transporter. ${ }^{27}$
Thus, it is possible that methylphenidate has an abuse potential similar to cocaine or D-amphetamine. However, according to the National Institute on Drug Abuse Community Epidemiology Work Group, actual abuse rates for methylphenidate appear to be much less than those for cocaine and D-amphetamine in the United States. ${ }^{28}$

In our sample, rates of cigarette smoking, alcohol use, and illicit drug use were significantly higher among undergraduate college students who used illicit methylphenidate than among those who used prescribed stimulants or who did not report any stimulant use. Not only were illicit methylphenidate users more likely to be polydrug users, they were also more likely to have begun drug use in high school or earlier, as compared with the other two groups. For instance, $91 \%$ of past-year illicit methylphenidate users had used marijuana in high school or before.

Notably, the drug-use behaviors of students using prescribed stimulants more closely resembled the drug-use behaviors of the nonstimulant users than they did the illicit methylphenidate users. This finding accords with the conclusions of a research group who determined that effective treatment of ADHD with psychostimulants, such as methylphenidate, may decrease young patients' risk of developing a substance use disorder. ${ }^{29}$ These researchers, after controlling for subjects' age, socioeconomic status, lifetime risk of conduct disorder at baseline, and lifetime history of substance abuse disorders in the subjects' parents, found that pharmacotherapy was associated with an 85\% reduction in the risk for substance abuse disorders in youths with ADHD. ${ }^{29}$ Although there is disagreement about the exact relationship between ADHD, psychostimulant use, and the risk for developing a substance use disorder, our sample of students using prescribed stimulants exhibited rates of substance use that were similar to those of nonstimulant users. These students may have experienced a protective effect from substance use by effective treatment with methylphenidate, although larger samples and additional information regarding ADHD diagnosis would be needed to establish this association clearly.

It is well known that alcohol or drug use behaviors cluster together with other problem behaviors. ${ }^{30}$ Our findings suggest that the factors associated with illicit methylphenidate use are very similar to those previously found to be associated with use of other illicit drugs among 
college students. ${ }^{1,31}$ Having a greater number of sex partners and engaging in frequent partying in college have been shown to be significantly associated with higher rates of marijuana ${ }^{31}$ and Ecstasy ${ }^{3}$ use. However, although these behaviors are associated with illicit drug use, the causal role of illicit methylphenidate use in our students who reported other risky behaviors or negative alcohol- or drug-related consequences cannot be clearly established.

According to the Drug Enforcement Administration, the overall production (aggregate production quota) of methylphenidate has increased dramatically since $1990 .{ }^{32}$ This increase in availability may partly reflect an increase in diversion, but it also may be indicative of a dramatic increase in recognition and diagnosis of ADHD, combined with realization that $A D H D$ symptoms often continue into adulthood. ${ }^{33}$ Although we did not set out to examine the diversion of prescribed methylphenidate, we found an apparent relationship between illicit methylphenidate use and prescription stimulant use in university residence halls. For instance, in six residence halls where there was no reported prescription stimulant use, there was also no reported illicit methylphenidate use. However, in three of four residence halls where prescription stimulant use was present, illicit methylphenidate use was reported. Limited sample sizes prevented us from detecting statistically significant differences in illicit methylphenidate use among particular residence halls. More research is needed in this area because diversion of prescribed stimulants has been documented among children and adolescents in both Canada and the United States. ${ }^{34,35}$

\section{Limitations}

Several limitations need to be considered when weighing the potential implications of this study. The survey question regarding prescribed stimulants included "weight loss pills" as an example in addition to "Ritalin," which limited our findings. Since we cannot assume that 100\% of respondents answering yes to the prescription stimulant response had taken methylphenidate for ADHD, based on information provided by the Drug Enforcement Administration and the Council on Scientific Affairs of the American Medical Association, approximately $80 \%$ of prescribed methylphenidate is used for children diagnosed with ADHD, ${ }^{32}$ and more than $90 \%$ of stimulant use for the treatment of ADHD in the
United States is methylphenidate. ${ }^{11}$

The survey question assessing illicit methylphenidate use did not carry the same limitation because it listed only Ritalin as a response. We did not determine the quantity of illicit methylphenidate that students used on each occasion, the reasons for use, or whether any respondents had taken methylphenidate intranasally.

The power of our statistical analyses, in particular the multivariate logistic regression, was limited by the number of students who reported prescribed stimulant use ( 25 students) and illicit methylphenidate use (57 students). Our findings regarding possible diversion were limited because our analysis was based on a probability sample of undergraduate students living in residence halls. Therefore, we could not accurately assess actual diversion rates based on the entire residence hall population. Also, we did not ask how illicit methylphenidate users were obtaining their methylphenidate. Finally, our study population consisted of a predominantly white and affluent group of undergraduate college students. More research is needed to compare our findings with those resulting from more diverse samples, including young adults not attending college.

\section{Implications for Future Practice}

Physicians and pharmacists must balance the risks and benefits of psychostimulant pharmacotherapy carefully when diagnosing, treating, and monitoring their patients. "Health care providers must cooperate in detecting abuse and minimizing diversion." 33 School social workers, nurses, and administrators should consider several prevention strategies when dealing with abusable prescription drugs; clearly, enhanced screening and assessment can lead to early identification of potential methylphenidate abusers.

Clinicians should be familiar with nonpsychostimulant alternatives for the treatment of ADHD and other disorders. For example, the Food and Drug Administration recently approved atomoxetine, a nonstimulant norepinephrine reuptake inhibitor that has been shown to be safe and effective for treatment of ADHD in children, adolescents, and adults. ${ }^{36}$ Alternatively, the use of pharmaceutical delivery systems that are not easily manipulated for injection or inhalation might help limit the abuse of methylphenidate and other prescription psychostimulants. For example, at least one published report describes 
failed attempts at abusing Concerta (methylphenidate; McNeil Consumer \& Specialty Pharmaceuticals, Fort Washington, PA) by the intranasal route. ${ }^{37}$ Concerta uses an osmotic pressure delivery system to deliver methylphenidate at a controlled rate. This system may be difficult to use by alternate routes of administration, due to its physical make-up and insoluble components. Finally, inappropriate use of prescription psychostimulants may be hindered by the use of centralized prescription databases, such as the newly introduced Michigan Automated Prescription System. ${ }^{38}$ This system, which allows clinicians to access patients' prescription records, allows for more thorough monitoring and detection of drug-seeking behaviors, such as doctor shopping or the use of multiple pharmacies to obtain controlled substances.

\section{Implications for Future Research}

Future research is needed to further clarify the relationships between ADHD, treatment with psychostimulants, and the risk for substance use in different populations (e.g., age, gender, race, socioeconomic status). Another important question is whether exposure to abusable psychoactive prescription drugs, such as psychostimulants, leads to a higher prevalence of other illicit substance use. Qualitative research should be used to examine the reasons for illicit methylphenidate use across different populations. Examples of reasons that should be explored are weight loss, euphoria, prolonging study time, and prolonging the effects of intoxicating agents such as alcohol. Furthermore, studies assessing the route of administration, particularly the intranasal route, should be conducted, as should be studies to determine whether certain dosage forms (e.g., long-acting preparations and osmotic delivery systems) have less abuse potential than other dosage forms. Longitudinal studies could determine patterns of illicit methylphenidate use in different populations. Such studies might help clarify the differences in patterns of abuse between methylphenidate and other illicit psychostimulants, such as cocaine and amphetamines. Longitudinal studies are also needed to examine how various patterns of illicit methylphenidate use during adolescence are related to long-term morbidity and mortality.

\section{Conclusion}

Of the 2250 students who completed our survey, 3\% reported past-year illicit methylphenidate use. These students were significantly more likely to use alcohol and drugs and report adverse alcohol- and drug-related consequences than prescription stimulant users or students who did not use stimulants. However, more work is needed to explore the problem of illicit use of prescription-only stimulants on college campuses. Such efforts can provide clinicians and researchers with a clear understanding and awareness of this potentially serious public health issue.

\section{Acknowledgments}

The authors gratefully acknowledge the assistance of MSInteractive in collecting data and Hannah d'Arcy for providing helpful comments on an earlier version of this manuscript.

\section{References}

1. Gledhill-Hoyt J, Lee H, Strote J, Wechsler H. Increased use of marijuana and other illicit drugs at US colleges in the 1990s: results of three national surveys. Addiction 2000;95:1655-67.

2. Johnston LD, O'Malley PM, Bachman JG. Monitoring the future national survey results on drug use, 1975-2000. Volume II: college students and adults ages 19-40. NIH publication no. 01-4925. Bethesda, MD: National Institute on Drug Abuse, 2001.

3. Strote J, Lee JE, Wechsler H. Increasing MDMA use among college students: results of a national survey. J Adolesc Health 2002;30:64-72.

4. Wechsler H, Lee JE, Kuo M, Seibring M, Nelson TF, Lee H. Trends in college binge drinking during a period of increased prevention efforts. Findings from $4 \mathrm{Harvard}$ School of Public Health college alcohol study surveys: 1993-2001. J Am Coll Health 2002;50:203-17.

5. Presley CA, Meilman PW, Cashin JR. Alcohol and drugs on American college campuses: use, consequences, and perceptions of the campus environment, volume IV: 1992-94. Carbondale, IL: Core Institute, Southern IIlinois University, 1996.

6. Abbey A. Alcohol-related sexual assault: a common problem among college students. J Stud Alcohol 2002;14(suppl): 118-28.

7. Hingson RW, Heeren T, Zakocs RC, Kopstein A, Wechsler H. Magnitude of alcohol-related mortality and morbidity among U.S. college students ages 18-24. J Stud Alcohol 2002;63: 136-44.

8. Perkins HW. Surveying the damage: a review of research on consequences of alcohol misuse in college populations. J Stud Alcohol 2002;14(suppl):91-100.

9. IMS Health. National prescription audit plus ${ }^{T M}$. Available from www.imshealth.com. Accessed July 2002.

10. Challman T, Lipsky JJ. M ethylphenidate: its pharmacology and uses. Mayo Clin Proc 2000;75:711-21.

11. Goldman LS, Genel M, Bezman RJ, Slanetz PJ. Diagnosis and treatment of attention-deficit/hyperactivity disorder in children and adolescents. Council on Scientific Affairs, American Medical Association. JAMA 1998;279:1100-7.

12. Johnston LD, O'Malley PM, Bachman JG. Monitoring the future national survey results on drug use, 1975-2000. Volume I: secondary school students. NIH publication no. 01-4924. Bethesda, MD: National Institute on Drug Abuse, 2001.

13. Johnston LD, O'Malley PM, Bachman JG. National survey results on drug use from the monitoring the future study, 1975-1998. Volume II: college students and young adults. NIH 
publication no. 99-4661. Bethesda, MD: National Institute on Drug Abuse, 1999.

14. Wechsler H, Davenport A, Dowdall G, Moeykens B, Castillo S. Health and behavioral consequences of binge drinking in college. A national survey of students at 140 campuses. JAMA 1994:272:1672-7.

15. McCabe SE. Gender differences in collegiate risk factors for heavy episodic drinking. J Stud Alcohol 2002;63:49-56.

16. McC abe SE, Boyd C, Couper M, Crawford S, D'Arcy H. Mode effects for collecting alcohol and other drug data: Web and U.S. mail. J Stud Alcohol 2002;63:755-61.

17. Indiana Resource Prevention Center. ATOD use by Indiana children and adolescents. Bloomington, IN : Institute for Drug Abuse Prevention, 1999

18. Babcock Q, Byrne T. Student perceptions of methylphenidate abuse at a public liberal arts college. J Am Coll Health 2000;49:143-5.

19. Goyer PF, Davis GC, Rapoport JL. Abuse of prescribed stimulant medication by a 13-year-old hyperactive boy. J Am Acad Child Adolesc Psychiatry 1979;18:170-5.

20. Levine B, Caplan YH, Kaufman G. Fatality resulting from methylphenidate overdose. J Anal Toxicol 1986;10:209-10.

21. Jaffe SL. Intranasal abuse of prescribed methylphenidate by an alcohol and drug abusing adolescent with ADHD. J Am Acad Child Adolesc Psychiatry 1991;30:773-5.

22. Parran TV Jr, Jasinski DR. Intravenous methylphenidate abuse: prototype for prescription drug abuse. Arch Intern Med 1991;151:781-3.

23. Garland EJ. Intranasal abuse of prescribed methylphenidate. J Am Acad Child Adolesc Psychiatry 1998;37:573-4.

24. Massello W III, Carpenter DA. A fatality due to the intranasal abuse of methylphenidate (Ritalin). J Forensic Sci 1999;44:220-1.

25. Kollins SH, MacDonald EK, Rush CR. Assessing the abuse potential of methylphenidate in nonhuman and human subjects: a review. Pharmacol Biochem Behav 2001;68:611-27.

26. Volkow ND, Ding YS, Fowler JS, et al. Is methylphenidate like cocaine? Studies on their pharmacokinetics and distribution in the human brain. Arch Gen Psychiatry 1995;52:456-63.

27. Volkow ND, Wang GJ, Fowler JS, et al. Methylphenidate and cocaine have a similar in vivo potency to block dopamine transporters in the human brain. Life Sci 1999;65:PL 7-12.

28. National Institute on Drug Abuse, Community Epidemiology Work Group. Epidemiologic trends in drug abuse. Volume I: highlights and executive summary. DHHS publication no. (NIH) 95-3988, Bethesda, MD: National Institute on Drug Abuse, 1995.

29. Biederman J, Wilens T, Mick E, Spencer T, Faraone SV. Pharmacotherapy of attention-deficit/hyperactivity disorder reduces risk for substance use disorder [online exclusive article]. Pediatrics 1999;104:e20. Available from www. pediatrics.org/cgi/content/full/104/2/e20. Accessed March 12, 2003.

30. Jessor R, Donovan JE, C osta FM. Beyond adolescence: problem behavior and young adult development. Cambridge, England: Cambridge University Press, 1991.

31. Bell R, Wechsler H, Johnston LD. Correlates of college student marijuana use: results of a US national survey. Addiction 1997;92:571-81.

32. Woodworth T. DEA congressional testimony, Committee on Education and the Workforce: Subcommittee on Early Childhood, Youth and Families, May 16, 2000. Available from www.usdoj.gov:80/dea/pubs/cngrtest/ct05/600.htm. Accessed March 12, 2003.

33. Llana ME, Crismon ML. Methylphenidate: increased abuse or appropriate use? J Am Pharm Assoc 1999:39:526-30.

34. Poulin C. Medical and nonmedical stimulant use among adolescents: from sanctioned to unsanctioned use. Can Med Assoc J 2001;165:1039-44.

35. Musser CJ, Ahmann PA, Theye FW, Mundt P, Broste SK, Mueller-Rizner N. Stimulant use and the potential for abuse in Wisconsin as reported by school administrators and longitudinally followed children. J Dev Behav Pediatr 1998;19:187-92.

36. Food and Drug Administration. FDA talk paper. FDA approves non-stimulant ADHD drug. Rockville, MD: U.S. Food and Drug Administration, N ovember 26, 2002.

37. Jaffe SL. Failed attempts at intranasal abuse of Concerta [letter]. J Am Acad Child Adolesc Psychiatry 2002;41:5.

38. Michigan Automated Prescription System. Health alert no. 121902. Lansing, MI: Consumer \& Industry Services, Bureau of Health Services, December 19, 2002. Available from www.michigan.gov/cis. Accessed March 12, 2003. 